NBER WORKING PAPER SERIES

\title{
AN EXAMINATION OF MULTIJURISDICTIONAL \\ CORPORATE INCOME TAXES UNDER \\ FORMULA APPORTIONMENT
}

\author{
Roger H. Gordon \\ John D. Wilson
}

Working Paper No. 1369

\section{NATIONAL BUREAU OF ECONOMIC RESEARCH \\ 1050 Massachusetts Avenue \\ Cambridge, MA 02138 \\ June 1984}

\begin{abstract}
We would like to thank Charles E. McLure, Jr., James R. Gault, and Mark Gersovitz for helpful discussion and comments. Most of the work on this paper was done while the first author was employed at Bell Laboratories. The research reported here is part of the NBER's research program in Taxation and project in Government Budget. Any opinions expressed are those of the authors and not those of the National Bureau of Economic Research or of AT\&T Bell Laboratories.
\end{abstract}


NBER Working Paper \#1369

June 1984

An Examination of Multijurisdictional Corporate

Income Taxes Under Formula Apportionment

\section{ABSTRACT}

This paper examines how corporate taxation of multijurisdictional firms using formula apportionment affects the incentives faced by individual firms and individual states. We find that formula apportionment creates factor price distortions which vary in general among firms within a state, and in such a way as often to put multistate firms at a competitive advantage. Formula apportionment also creates incentives for cross-hauling of output, with production in low tax rate states more profitably sold in high tax rate states, and conversely. Politically, formula apportionment appears to be very unstable--states face an incentive to shift to some other form of taxation. None of these problems exist when a corporate tax uses separate accounting.

Roger H. Gordon Department of Economics University of Michigan Ann Arbor, MI 48109
John D. Wilson Department of Economics Columbia University New York, NY 10027 


\section{An Examization of Multijurisdictional Corcorate \\ Income Taxes Under Formula Apportionment}

\section{Roger H. Gordon*}

University of Michigan and National Bureau of Economic Research

and

John D. Wilson*

Columbia University

Taxation of corporate income becomes administratively quite complicated when a corporation is located in more than one taxing jurisdiction. National governments, in taxing a multinational firm, have aftempted to establish separate conomic accounting for the activity of such a firm in cach country. This approach creates the difficulty that non-marketed intermediate goods transferred across borders must be priced, however arbitrarily. In contrast, U.S. state governments, in taxing a multistate firm, have adopted one of various formulas to apportion the total profits of the firm among the various states where it does business. ${ }^{1}$ With formula apportionment, internal prices need not be established. This advantage is sufficient that in recent years there has been some interest in replacing separate accounting with formula apportionment when taxing multinational firms. ${ }^{2}$

In addition to simplifying tax administration, however, this paper shows that use of formula apportionment also changes in complicated ways the incentives faced by both individual firms and individual states. When international profits are apportioned, use of the tax by U.S. states directly affects incentives to invest 
abroad, even without any change in market interest rates or other prices, though the direction of the effect depends on the relative tax rates and the specific definition of taxable income. Most states use a three part apportionment formula, basing the apportionment on the location of sales, payroll, and property. Unfortunately, the interactions among the three factors make analysis of the general case extremely complicated. In this paper, we analyze first the effects of formula apportionment based simply on the location of a single factor, property. We then examine the degree to which the conclusions generalize to a two-factor formula, based on property and payroll. We explore only briefly the three-factor case. In the last section, we discuss some alternative formulas.

Our analysis is confined to characterizing the equilibrium behavior of individual firms and individual states when formula apportionment is used. No attempt is made to examine the general equilibrium incidence of the tax, the focus of most previous work on state corporate taxes. 3

In analyzing these taxes, we examine first the nature of the investment distortions created by the tax. We then characterize the equilibrium locational pattern of firms. Finally, we explore when states would find it advantageous to shift to some other form of taxation.

\section{Single factor tax based on property}

In the United States, the most common formula for apportioning corporate income among the various states uses three factors: sales, payroll, and property. If $\tau_{i}$ is the statutory corporate income tax rate in state $i$, if $S_{i}, W_{i}$, and $K_{i}$ represent 
sales, payroll, and property, respectively in state $i$, and if $\pi_{x i}$ represents total profits of a firm, as defined by the tax law in state $i$, then the tax due by a firm to state $i$ can be expressed as

$$
\frac{\tau_{i}}{3}\left[\frac{S_{i}}{\sum_{j} S_{j}}+\frac{W_{i}}{\sum_{j} W_{j}}+\frac{K_{i}}{\sum_{j} K_{j}}\right] \pi_{x i}
$$

This is the formula recommended by the Multistate Tax Commission, though not all states have adopted it. Some states do not weight the three factors equally, and others use fewer factors.

Because of the surprising complexity of analyzing a multi-factor case directly, we analyze first the one-factor tax based on property. We examine in turn the effocts of the tax on the incentives faced by individual firms and individual states. The analysis of this case is very simple, even compared with that of alternative one-factor taxes, and yet the conclusions reached here are very similar to those reached in section II for the two-factor case.

A. Incentives faced by corporations.

If the tax law involves a one-factor formula based on property, then the tax due in state $i$ would simplify to $\tau_{i} K_{i} \pi_{x i} / \sum_{j} K_{j}$. Total taxes paid by the firm would equal $\sum_{i}\left(\tau_{i} K_{i} \pi_{x i}\right) / \sum_{j} K_{j}$. In making investment decisions, the objective of the firm would be to maximize pretax oconomic profits, ${ }^{4}$ denoted by $\pi$, minus any taxes due. While taxable profits differ from economic profits in complicated ways, and ways which vary by state and by type of capital, we assume for simplicity that 
$\pi_{x i}=\pi+d K$, where $K \equiv \sum_{j} K_{j}$. Here, $d$ captures the degree to which the investment tax credit, depreciation deductions, and interest deductions, fall short of the opportunity cost of capital..$^{5}$ We ignore variation of $d$ by state. While the value of $d$ implicitly depends on the market interest rate, our analysis is confined to situations where the interest rate remains unchanged.

The firm is assumed to use two inputs to production in each state $i$ : capital, $K_{i}$, and labor, $L_{i}$. For simplicity, we assume throughout the paper that capital is completely mobile between states while labor is completely immobile. Implicitly, we therefore assume that production occurs in every state; wage rates are cnough lower in high tax rate states so as to attract sufficient production to employ all of the workers there. The firm chooses how much capital and labor to cmploy in cach state so as to maximize

$$
R \equiv \pi-\sum_{i} \tau_{i} K_{i}(\pi+d K) / K
$$

where $R$ equals the after tax economic profits of the firm. The first order conditions for the optimal $K_{i}$ imply that

$$
\begin{aligned}
\frac{\partial \pi}{\partial K_{i}} & =\frac{\tau_{i} d}{1-\bar{\tau}_{K}}+\frac{\pi}{K} \cdot \frac{\left(\tau_{i}-\bar{\tau}_{K}\right)}{\left(1-\bar{\tau}_{K}\right)} \\
& =\frac{d\left(\tau_{i}-\bar{\tau}_{K}^{2}\right)}{\left(1-\bar{\tau}_{K}\right)^{2}}+\frac{R}{K} \frac{\left(\tau_{i}-\bar{\tau}_{K}\right)}{\left(1-\bar{\tau}_{K}\right)^{2}} \text { for all } i .
\end{aligned}
$$

Here, $\bar{\tau}_{K} \equiv \sum_{j} \tau_{j} K_{j} / K$ represents the weighted average statutory tax rate. In contrast, $\partial \pi / \partial L_{i}=0$, as would occur without taxes. 
Decisions are clearly distorted by the tax, since $\partial \pi d \partial K_{i} \neq 0$. However, not only does the tax distortion to the marginal cost of capital differ across states, due to differences in the $\tau_{i}$, but it also varies by firm within any state, since $\bar{\tau}_{K}$ and $R / K$ may vary by firm. Such distortions within a state exist even if that state does not tax corporate profits, so that $\tau_{i}=0$. In such a state, marginal investment would be subsidized. ${ }^{6}$

A more striking observation is that formula apportionment creates incentives for firms in different states to merge. Consider for example two firms, one operating solely in a state with no corporate tax and the other operating in a state with a tax rate $\tau$. Assume each employs one unit of capital, and is initially breaking even. The first then earns zero economic profits while the second must earn $\tau d /(1-\tau)$ to break even after tax. Tax payments equal $\tau(d+\tau d /(1-\tau))$. If the two firms merge, tax payments become $(\tau / 2)(2 d+\tau d /(1-\tau))$. The tax on the normal return, $d$, remains unchanged, but the tax on oconomic profits is halved. While all the economic profits are carned in the taxing state, only half are attributed to that state after the merger under formula apportionment.

In fact, if all firms have access to the same constant returns to scale technology and if after tax profits, $R$, arc sufficiently small (assumptions maintained throughout the rest of the paper), then a firm located solely in state $i$ should be at a competitive disadvantage with respect to any firm in state $i$ with branches in other states. For consider two potential firms, each intending to use the same factor proportions in state $i$, but one having branches elsewhere. Assume no 
efficiency gain, or loss, from maintaining branches in different states. When the first firm employs a unit of capital, its tax payments are $\tau_{i}\left(\partial \pi_{i} / \partial K_{i}+d\right)$. In contrast, when the second firm ermploys a unit of capital, its taxes go up by

$$
\bar{\tau}_{K}\left(\frac{\partial \pi_{i}}{\partial K_{i}}+d\right)+\left(\tau_{i}-\bar{\tau}_{K}\right)\left(\frac{\pi}{K}+d\right)
$$

The first firm pays more in taxes by an amount equal to $\left(\tau_{i}-\bar{\tau}_{K}\right)\left(\partial \pi_{i} / \partial K_{i}-\pi / K\right)$. Under our assumptions, $\partial \pi_{i} / \partial K_{i} \approx \pi_{i} / K_{i}$, so that this expression is positive as long as $\pi_{i} / K_{i}>\pi / K$ whenever $\tau_{i}>\bar{\tau}_{K}$, and conversely. 'These conditions would be satisfied unless true profits are large and concentrated in the low tax rate states.

More generally, if the production function, shared by all firms, is quasi-concave (an assumption also maintained throughout the rest of the paper), then competition drives firms to spread their operations across states until they all posses identical $\bar{\tau}_{K}$ 's. To see this, let $\pi(V)$ be the function relating before tax profits to the vector of capital and labor inputs in each state. Consider two firms employing input vectors, $V^{1}$ and $V^{2}$, which yield different $\bar{\tau}_{K}$ 's, $\bar{\tau}_{K}^{1}$ and $\bar{\tau}_{K}^{2}$. Assume that each firm obtains zero after tax profits, as required for an equilibrium under the assumption of constant returns to scale. Then firm $i$ 's tax payments are $T^{i}=\pi\left(V^{i}\right)=\left[\tau_{K}^{i} /\left(1-\bar{\tau}_{K}^{i}\right)\right] d K^{i} ;$ and total after tax profits for the two firms satisfy

$$
R^{1}+R^{2}=\left(\pi\left(V^{1}\right)+\pi\left(V^{2}\right)\right)-\left(\frac{\bar{\tau}_{K}^{1}}{1-\bar{\tau}_{K}} \lambda^{1}+\frac{\bar{\tau}_{K}^{2}}{1-\bar{\tau}_{K}^{2}} \lambda^{2}\right) d\left(K^{1}+K^{2}\right)=0 ;(3 a)
$$

where 


$$
\lambda^{i}=\frac{K^{i}}{K^{1}+K^{2}}
$$

Suppose now that the two firms merge for tax purposes, but do not alter their total factor demands, $V^{1}+V^{2}$. Total after tax profits become

$$
R^{12}=\left(1-\bar{\lambda}_{K}^{12}\right)\left[\pi\left(V^{1}+V^{2}\right)-\frac{\bar{\tau}_{k}^{12}}{1-\bar{\tau}_{K}^{12}} d\left(K^{1}+K^{2}\right)\right]
$$

where

$$
\bar{\tau}_{K}^{12}=\sum_{j} \tau_{j} \frac{K_{j}^{1}+K_{j}^{2}}{K^{1}+K^{2}}=\bar{\tau}_{K}^{1} \lambda^{1}+\bar{\tau}_{K}^{2} \lambda^{2}
$$

Since $\bar{\tau}_{K} /\left(1-\bar{\tau}_{K}\right)$ is a strictly convex function of $\bar{\tau}_{K}$, $\bar{\tau}_{K}^{12} /\left(1-\bar{\tau}_{K}^{12}\right)<\left[\tau_{K}^{1} /\left(1-\bar{\tau}_{K}^{1}\right)\right] \lambda^{1}+\left[\bar{\tau}_{K}^{2} /\left(1-\tau_{K}^{2}\right)\right] \lambda^{2}$. Furthermore, $\pi\left(V^{1}+V^{2}\right) \geq \pi\left(V^{1}\right)+\pi\left(V^{2}\right)$ under our assumptions about production. It then follows from (3) and (4) that the merger raises total profits: $R^{12}>R^{1}+R^{2}$

Thus, there exists tax induced pressure for firms to diversify (or merge with competitors in other states) until they all possess identical $\bar{\tau}_{K}$ 's. This pressure represents a separate form of tax distortion from that affecting the capital-labor ratio in any state. It does not arise when separate accounting, rather than formula apportionment, is used. ${ }^{8}$

The amount of taxes saved through merger in the above example, as a fraction of initial tax payments, assuming no efficiency gain from merger, would equal 


$$
\frac{\left(\bar{\tau}_{K}^{1}-\bar{\tau}_{K}^{2}\right)^{2} K^{1} K^{2}}{\left(K^{1}+K^{2}\right)\left(\left(1-\bar{\tau}_{K}^{2}\right) \bar{\tau}_{K}^{1} K^{1}+\left(1-\bar{\tau}_{K}^{1}\right) \bar{\tau}_{K}^{2} K^{2}\right)}
$$

If, for simplicity, $K^{1}=K^{2}$ and $\bar{\tau}_{K}^{2}=0$, then this expression reduces to $\bar{\tau}_{K}^{1} / 2$. While this saving is quite modest at the level of tax rates characteristic of U.S. state corporate taxes, it would be substantial if formula apportionment were used by national governments.

This result about diversification does not rule out the possibility that all production of a particular good will be located in one state bocause of some comparative advantage of production in that state. It implies that the firms producing the good will face competitive pressure to merge, if only for tax purposes, with firms located in other states, regardless of the composition of their output, and to do so until they achieve the common $\bar{\tau}_{K}$.

B. Distributional considerations between states.

States can tax corporate capital in various ways. In addition to using a corporate tax based on formula apportionment, states can use a property tax or a corporate tax based on separate accounting. Their choice among taxes will depend on more than administrative simplicity. In this section, we argue that formula apportionment aids low tax rate states at the expense of high tax rate states. Consequently, high tax rate states have an incentive to switch unilateraly to separate accounting or property taxation.

Assume that all production is characterized by constant returns to scale, and all firms face the same $\bar{\tau}_{K}$, as motivated above. Then $\pi / K$ is identical across firms. 
Under formula apportionment, the tax payments made by a given firm to state $i$ satisfy

$$
T_{i}=\tau_{i} K_{i} B
$$

where

$$
B=(\pi / K+d)
$$

We shall call $B$ the "tax base" per unit of capital.

A crucial property of formula approtionment is that all states share the same tax base. Furthermore, additional investment in any single state alters this common tax base. In particular, the first-order conditions for profit maximization (eq. (2)) give

$$
\frac{\partial B}{\partial K_{i}}=\frac{\left(\tau_{i}-\bar{\tau}_{K}\right) d}{K\left(1-\bar{\tau}_{K}\right)^{2}}
$$

Thus investment in a high tax rate state $\left(\tau_{i}>\bar{\tau}_{K}\right)$ benefits other states by raising the tax base; while investment in a low tax rate state harms other states. 'The basic reasoning is that, if $\tau_{i}>\bar{\tau}_{K}$, then an increase in $K_{i}$ raises (lowers) $\bar{\tau}_{K}$, which necessitates a rise (fall) in $B=(\pi / K+d)$ to maintain zero net profits, as required by profit maximization.

Thus, there is an externality associated with a firm's investment in a given state. As a result, the marginal distortion, $\partial \pi / \partial K_{i}$, differs from the average tax revenue, $T_{i} / K_{i}$, which state $i$ obtains from the firm. To calculate the difference, let $T$ be the firm's total tax payments, summed over all states, and note that profit 
maximization implies that $\partial \pi / \partial K_{i}=\partial T / \partial K_{i}$. Eq. (6) then gives

$$
\frac{\partial \pi}{\partial K_{i}}=\frac{T_{i}}{K_{i}}+\frac{\bar{\tau}_{K}\left(\tau_{i}-\bar{\tau}_{K}\right) d}{\left(1-\bar{\tau}_{K}\right)^{2}}
$$

It follows that

$$
\frac{\partial \pi}{\partial K_{i}} \geq \frac{T_{i}}{K_{i}} \text { as } \tau_{i} \geq \bar{\tau}_{K}
$$

Note that $T_{i} / K_{i}$ equals state $i$ 's average tax revenue, since $\partial \pi / \partial K_{i}$ and $T_{i} / K_{i}$ are identical across firms under the assumption of identical $\bar{\tau}_{K}$ s.

Under formula apportionment, therefore, revenue is effoctively transferrel from high tax states to low tax states with this transfer taking the form of subsidies on investment in low tax rate states and surtaxes on investment in high tax rate states. To make this interpretation more rigorous, let us introduce some additional assumptions which allow us to isolate the distributional effects of formula apportionment without adding general equilibrium complications:

Assumption A. All goods are perfectly mobile between states.

Assumption B. All individuals possess identical homothetic utility functions over goods; and each state government spends its tax revenue in the same way as consumers.

Suppose now that formula apportionment is replaced by a separate accounting system where each state's tax rate $\tau_{i}^{S}$, is set so as to produce the same marginal distortion in that state as existed under formula apportionment. Under our assumptions, this change does not alter the total demand for each good, or the total 
quantity of each factor employed in each region. All equilibrium prices remain unchanged. But the change does redistribute tax revenue between states. Under separate accounting, state $i$ 's average tax revenue is

$$
\frac{T_{i}}{K_{i}}=\tau_{i}^{s}\left(\frac{\pi_{i}}{K_{i}}+d\right)=\frac{\tau_{i}^{S}}{1-\tau_{i}^{S}} d
$$

where $\pi_{i} / K_{i}$ is each firm's before tax profits per unit of capital in state $i$. Proiit maximization then implies that the marginal distortion satisfies

$$
\frac{\partial \pi}{\partial K_{i}}=\frac{\tau_{i}^{S}}{1-\tau_{i}^{S}} d=\frac{\tau_{i}}{K_{i}}
$$

Comparing (10) with $(7)$, we see that the shift to separate accounting raises state $i$ 's average tax revenue by $\left[\bar{\tau}_{K}\left(\tau_{i}-\bar{\tau}_{K}\right) d\right] /\left(1-\bar{\tau}_{K}\right)^{2}$, whercas $i$ 's total capital stock remains unchanged because the marginal distortion is fixed. Consequently, states with above average tax rates under formula apportionment gain by a universal shift to separate accounting, and conversely. ${ }^{9}$

C. Political instability of formula apportionment.

Since, under formula apportionment, low tax rate states are in effect subsidized at the expense of high tax rate states, any state using formula apportionment would in general gain by lowering its corporate tax rate to zcro, maximizing its transfer from other states under formula apportionment, then replacing the lost revenue with, for example, a corporate property tax. Spocifically, let state $i$ switch to a property tax at rate $t_{i}$, which produces the same revenue per dollar of capital as was previously collected under formula apportionment. With no pure profits, and 
assuming a common $\bar{\tau}_{K}$ across firms, this implies that $t_{i}=\tau_{i} d /\left(1-\bar{\tau}_{K}\right)$, using the $\bar{\tau}_{K}$ prevailing before the switch. Assume that the state is small, so that the switch does not significantly affoct the net return to capital or the average tax rate, $\bar{\tau}_{K}$. Following U.S. state tax law, assume also that property tax payments are deductible from taxable profits. Then, after the tax change, equation (2) is replaced by

$$
\frac{\partial \pi}{\partial K_{i}}=t_{i}-\frac{d \hat{\tau}_{K}^{2}}{\left(1-\hat{\tau}_{K}\right)^{2}} \approx \frac{\tau_{i} d}{\left(1-\bar{\tau}_{K}\right)}-\frac{d \bar{\tau}_{K}^{2}}{\left(1-\bar{\tau}_{K}\right)^{2}}
$$

where $\hat{\tau}_{K}$ is the weighted average tax rate in the new equilibrium. This distortion is algebraically smaller than the initial distortion, attracting more capital into the state, and therefore raising tax revenues and wage rates within the state. Politically, formula approtionment is very unstable.

An issue related to the political stability of formula apportionment concerns how nonparticipating states are affected by the nature of the apportionment formula. An example of political interest at the current time is how foreign countries or multinational firms are affected by having U.S. states apportion world-wide profits rather than domestic profits of a firm. The outcome depends critically on whether foreign taxes on corporate capital are deductible from taxable profits as defined by U.S. state corporate tax law. If the taxes are deductible, then foreign countries gain by having U.S. states apportion world-wide profits. To see this, assume that a foreign country has a proportional $\operatorname{tax}^{10}$ at rate $t_{F}$ on a U.S. firm's capital, $K_{F}$, invested in the country. Then the marginal distortion to capital 
investment there is $\partial \pi / \partial K_{F}=t_{F}$ when U.S. states apportion only domestic profits. But if U.S. states apportion world-wide profits, then analogous to equation (2b) we have

$$
\frac{\partial \pi}{\partial K_{F}}=t_{F}-\frac{\tilde{\tau}_{K}^{2} d}{\left(1-\tilde{\tau}_{K}^{2}\right)} .
$$

Here, $\bar{\tau}_{K}=\bar{\tau}_{K} K_{D} /\left(K_{D}+K_{F}\right)$, where $K_{D}$ is the firm's capital invested in the U.S. As before, we assume that $\tilde{\tau}_{K}$ is identical across firms, implying that $\partial \tau^{d} \partial K_{F}$ is also identical. Equation (2c) shows that the switch to apportioning world-wide profits lowers the common $\partial \pi / \partial K_{F}$, thereby raising investment abroad and increasing foreign tax revenue.

However, foreign corporate income tax payments are not currently deductible under U.S. state tax law. As a result, foreign countries and multinational firms lose (gain) by having U.S. state corporate taxes apportion world-wide profits rather than domestic profits if foreign tax rates are higher (lower) than U.S. state tax rates. To see this, consider a multinational firm initially facing a U.S. state corporate $\operatorname{tax}, \bar{\tau}_{X}$, based on formula apportionment of domestic profits, and a proportional tax on capital, at rate $t_{F}$, in a foreign country. Then total pretax profits in equilibrium must satisfy

$$
\pi=t_{F} K_{F}+\frac{\bar{\tau}_{K} d K_{D}}{\left(1-\bar{\tau}_{K}\right)}
$$

If U.S. states switch to apportioning world-wide profits, with no deduction for foreign taxes, the firm's pretax profits must now satisfy 


$$
\pi^{*}=\left(t_{F} K_{F}+\bar{\tau}_{K} d K\right) /\left(1-\bar{\tau}_{K}\right)
$$

where $K=K_{D}+K_{F}$. Simple algebra shows that, with no reallocation of capital, $\pi^{*}>\pi$ if $t_{F}>\frac{\bar{\tau}_{K} d}{\left(1-\bar{\tau}_{K}\right)}$, and conversely. If foreign tax rates are higher, required profits rise, and conversely.

Using equation (12), it is possible to show that apportioning world-wide profits, with no deduction of foreign taxes, implies that

$$
\frac{\partial \pi}{\partial K_{F}}=t_{F}+\frac{\bar{\tau}_{K}\left(1-\bar{\tau}_{K}\right) K_{D}}{\left(1-\bar{\tau}_{K}\right)^{2} K}\left(t_{F}-\frac{d \bar{\tau}_{K}}{\left(1-\bar{\tau}_{K}\right)}\right) .
$$

The second term in equation (13) reflects the marginal effect of $K_{F}$ on the tax base, $B$, used under formula apportionment. If $t_{F}>\bar{\tau}_{K} d /\left(1-\bar{\tau}_{K}\right)$, then an increase in $K_{F}$ raises $B$, in which case foreign investment benefits the U.S. In this case, the switch to apportioning world-wide profits raises $\partial \pi / \partial K_{F}$, thereby discouraging foreign investment and lowering foreign tax revenue. Given that foreign tax rates are generally much higher than U.S. state corporate tax rates, foreign countries and multinational firms are both made worse off by the tax change."

D. Government decision-making

If all states charge the same tax rate $\tau_{i}$ under formula apportionment, no transfers between states occur. We have argued, however, that each, acting unilaterally, would still gain by switching to a property tax. But also, the states 
would generally gain even if they all simultaneously switched to a property tax (or to separate accounting), still avoiding transfers between states, because they would be induced to make more efficient decisions. The basic intuition is that under formula apportionment, when a state raises its tax rate to increase revenues, its revenues go up by less than they would under separate accounting or under a property tax, for any given increase in the tax distortion affocting the cost of capital. Under formula apportionment, therefore, raising revenue is hardex, tax rates will be lower, and utility should be lower.

To formalize the argument, let us express the objective function of any state as a positive function of tax revenues collected (public expenditures), $T_{s i}$, and a negative function of the tax distortion to the cost of capital (incrcased prices), ${ }^{12}$ so that $V_{i}=V\left(T_{s i}, \partial \pi / \partial K_{i}\right)$. To isolate possible inefficiencies in the equilibrium level of tax revenue, we assume that the voctor of public goods financed by a given $T_{i}$, and the production techniques used to produce this vector, do not change when formula apportionment is replaced by separate accounting or property taxation. For simplicity, we also assume that all states have the same preferences and face identical tradeoffs, and that each state is sufficiently small that it treats the interest rate, and so $d$, as fixed.

Under separate accounting or a property tax, each state sets its tax rate so as to maximize

$$
V_{i}=V\left(K_{s i} \frac{\partial \pi}{\partial K_{i}}, \frac{\partial \pi}{\partial K_{i}}\right)
$$


where $K_{s i}$ is the state's total capital stock. The resulting cquilibrium $T_{s i}$ is likely to be inefficiently low. Each state treats as a loss the capital outflow resulting from a rise in its tax rate, but ignores the benefit which other states roceive from this outflow. The presence of this positive externality lowers. $T_{i}$ below its efficient level..$^{13}$

This externality is also present under formula apportionment. But there is a second externality which further reduces $T_{i}$ below its efficient level. Under formula apportionment, each state acts so as to maximize

$$
V_{i}=V\left(K_{s i} \frac{\partial \pi}{\partial K_{i}}-\frac{\left(\tau_{i}-\bar{\tau}_{K}\right) \bar{\tau}_{K} d K_{s i}}{\left(1-\bar{\tau}_{K}\right)^{2}}, \frac{\partial \pi}{\partial K_{i}}\right)
$$

Since all states are assumed to be identical, in equilibrium $\tau_{i}$ equals $\bar{\tau}_{K}$ and the extra term drops out. When each state acts in isolation, however, it must take into account this extra term, which lowers the tax rate selected. Under formula apportionment, each state perceives a less favorable trade off than it would under separate accounting or a property tax, even though colloctively the trade offs are identical. Each state ignores the increased subsidy to other states resulting from an increase in its own tax rate, so chooses tax rates which are inefficiently low, everything else equal. As a result, equilibrium utility will be lower under formula apportionment, everything else equal, and states would gain by switching to one of the alternative taxes. ${ }^{14}$ 
II. Two factor formula based on property and payroll

\section{A. Incentives faced by corporations}

Analysis of the two factor formula is much more complicated. While, in general, the conclusions here are similar to those found in soction I, several previous results reverse if the elasticity of substitution between capital and labor in production is too high.

If a two factor formula based on property and payroll is used, then the firm would allocate capital and labor so as to maximize

$$
R=\pi-\sum_{i} \tau_{i}\left(\alpha \frac{K_{i}}{K}+(1-\alpha) \frac{W_{i}}{W}\right)(\eta+d K)
$$

To capture the fact that weights on the two factors may vary, we have allowed for arbitrary weights, $\alpha$ and $(1-\alpha)$, on each factor used in the formula.

Assuming that competition drives $R$ to zero in equilibrium, the first order conditions for the optimal $K_{i}$ imply that

$$
\frac{\partial \pi}{\partial K_{i}}=\frac{\bar{\tau} d}{(1-\bar{\tau})}+\frac{\alpha\left(\tau_{i}-\bar{\tau}_{K}\right) d}{(1-\tau)^{2}} \text { for all } i
$$

Here, $\bar{\tau}=\alpha \bar{\tau}_{K}+(1-\alpha) \bar{\tau}_{W}$, where $\bar{\tau}_{W}=\sum_{i} \tau_{i} W_{i} / W$. As before, the cost of capital for firms in state $i$ varies across firms, depending on the average tax rates $\bar{\tau}$ and $\bar{\tau}_{K}$ each faces.

The first order conditions for the optimal $L_{i}$ imply that 


$$
\frac{\partial \pi}{\partial L_{i}}=\frac{(1-\alpha) w_{i}\left(\tau_{i}-\bar{\tau}_{W}\right) d K}{W(1-\bar{\tau})^{2}} \text { for all } i
$$

where $w_{i}$ is the wage rate in state $i$. Labor demand docisions are now distorted for firms with $\bar{\tau}_{W} \neq \tau_{i}$. The cost of labor is above the wage when $\bar{\tau}_{W}<\tau_{i}$, and conversely.

The average distortion to the cost of labor, $\left(\underset{i}{\sum} L_{i} \partial \pi / \partial L_{i}\right) / L$, is zero. In contrast, the average distortion to the cost of capital is $\bar{\tau} d /(1-\bar{\tau})$. We show below that the optimal capital-labor ratio in every state is a declining function of $\bar{\tau}$. However, it is not necessarily the case that the capital-labor ratio is lower high tax rate states than in low tax rate states. For example, when $\alpha=0$, the distortion to the cost of labor, $\partial \pi / \partial L_{i}$, is higher in higher tax rate states (unless $w_{i}$ adjusts to fully absorb the difference in tax rates), whereas the distortion to the cost of capital is identical across states.

Competitive pressure no longer necessarily leads firms to face equal $\bar{\tau}_{W}$ and $\bar{\tau}_{K}$ in cquilibrium. In fact, each firm may now have an incentive to produce in only one state. This possibility can be explained graphically. Consider an economy with two states, where $\tau_{1}>\tau_{2}$; and assume that the economy is in equilibrium with some firm producing in both states. With constant returns to scale, this firm's profits equal zero in each state when costs are evaluated at factor prices equal to the marginal costs of capital and labor (gross of marginal taxes). The firm's profit maximizing input vector in state 1 is illustrated in Fig. 1 by the tangency between the isoquant, $I$, for producing a dollar of revenue and the unit isocost curve, $C C$. 


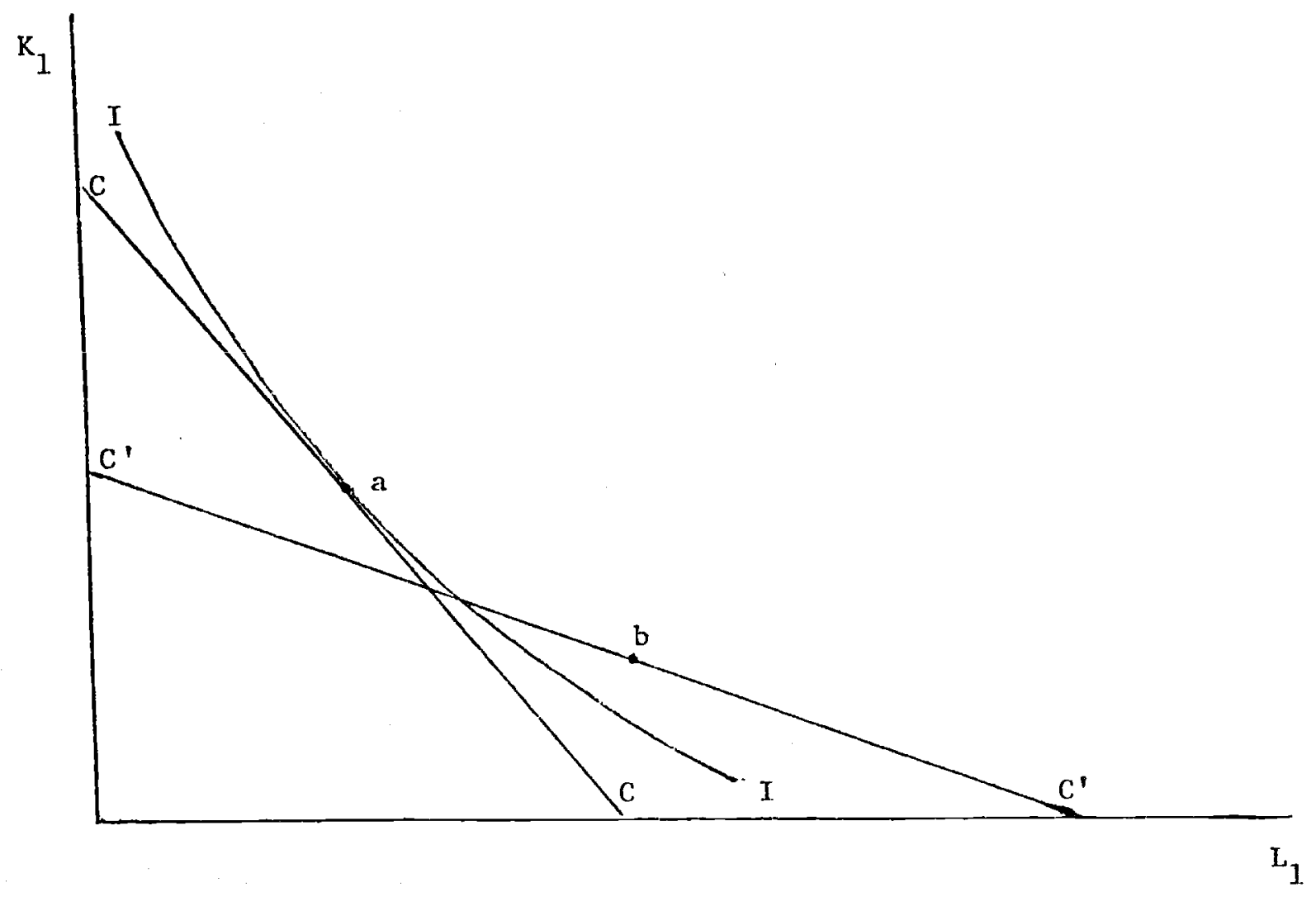

FIGURE 1 
The slope of $C C$ equals the ratio of the marginal cost of labor to the marginal cost of capital.

Suppose now that the firm eliminates all of its operations in state 2 without changing its input voctor in state 1. Assume that production is separable between states, so that $\partial \pi / \partial K_{1}$ and $\partial \pi / \partial L_{1}$ do not depend on $K_{2}$ and $L_{2}$. Then $\partial \pi / \partial K_{1}$ and $\partial \pi / \partial L_{1}$ remain unchanged (they continue to satisfy (16) and (17)), while the matginal taxes on labor and capital bocome

$$
\frac{\partial T}{\partial L_{1}}=\tau_{1}\left(\frac{\partial \pi}{\partial L_{1}}\right)
$$

and

$$
\frac{\partial T}{\partial K_{1}}=\tau_{1}\left(\frac{\partial \pi}{\partial K_{1}}+d\right)
$$

Since $\partial T / \partial L_{1}$ initially equals $\partial \pi / \partial L_{1}$ (by profit maximization), it is evident that specializing production in state 1 lowers $\partial T / \partial L_{1}$ though normally raises $\partial T / \partial K_{1}$. The unit isocost curve associated with the new marginal taxes, $C^{\prime} C^{\prime}$ in Fig. 1, must therefore intercept the $L_{1^{-}}$axis beyond $C C$. If labor and capital are sufficiently substitutable in production, so that the "curvature" of the isoquant is sufficiently small, the firm can move to an input vector on $C^{\prime} C^{\prime}$ which lies above the unit isoquant (e.g. point $b$ ). Although this move alters the marginal taxes on labor and capital, a high substitution elasticity between inputs insures that these changes are small (because $\partial \pi / \partial K_{1}$ and $\partial \pi \partial L_{1}$ are then insensitive to changes in the input vector). Consequently, although $C^{\prime} C^{\prime}$ is drawn for fixed marginal costs, its location 
above the unit iscquant at $b$ implies that positive profits can be made. Evidently, when the substitution elasticity is sufficiently high, each firm faces tax pressure to operate in only one state. While we have not succeeded in charactcrizing simply the nature of the equilibrium locational pattern of firms in the general case, given the complexity of the tax law, we have proven the following two theorems for special cases. In each case, we assume that there is a single good produced in the economy, which can be costlessly transported betwoen states, and that capital remains completely mobile while labor is completely immobile. Each theorem shows that competition leads firms to diversify across states unless the elasticity of substitution between capital and labor in the production function is "too high". We let $\sigma$ denote this elasticity. Since the proofs are quite long, they are reported in an appendix.

Theorem 1. Assume:

(1) $\alpha=0$, so only the payroll factor enters the apportionment tax formula.

(2) there is one output which is freely transported;

(3) $d$ is less than or equal to the net rate of return to capital, and

(4) the production technology is described by a C.E.S. production function which is identical across states and firms.

Then, if $\sigma \leq 2$, all firms will face the same $\bar{\tau}_{W}$ in cquilibrium.

Theorem 2. Assume that there are two states and that assumptions (2)-(4) in Theorem 1 hold, and that $\sigma<2 \min \left(\theta_{L}^{i}, \theta_{L}^{2}\right)$, where $\theta_{L}^{i}$ is the fraction of revenue 
spent of labor in state $i$ in the particular context described in the Appendix. Then each firm produces a positive amount of output in each state.

Since observed values of $\theta_{L}$ are in the range of 0.7 to 0.8 , and estimated values of $\sigma$ are rarely higher than 1.0 , the condition on $\alpha$ in Theorem 2 would seem very likely to be satisfied. ${ }^{15}$ Unlike Theorem 1 , however, Theorem 2 does not rule out the possibility that different firms possess different average tax rates, because there may still exist two production plans which maximize net profits, yet each involving positive output in both states.

The assumption that the production function is C.E.S. is iraposed for simplicity. The proofs hold for any constant returns to scale production function which satisfies the stated conditions on the substitution elasticity.

The requirement that or is less than $2 \min \left(\theta_{L}^{1}, \theta_{L}^{2}\right)$ may seem quite weak-most empirical estimates of $\sigma$ are less than one. However, if more than one good is produced in a state, and if the isoquants for each have different shapes, then the composite isoquant describing the factor inputs which produce a given value of output will have linear segments. These arise as the firm shifts the relative composition of its output from one good to another, bolding constant the capitallabor ratio used for each. But along any linear segment the elasticity of substitution between capital and labor is infinite, violating the conditions of the theorem. Further characterizing the cquilibrium with multiple outputs in the two factor case is very difficult. If $\alpha=0$, however, we have been able to show that: (1) all firms which produce any given good will in equilibrium face the same $\bar{\tau}_{W}$ if 
the production function for that good is characterizal by $o<2$, but (2) diffcrent $\bar{\tau}_{W}$ 's must exist in equilibrium. ${ }^{16}$ Formula apportionment creates complex pressures affecting the merger of firms, encouraging some mergers and discouraging others. Separate accounting, in contrast, has no effect on incentives to merge.

B. Distributional considerations between states

Will states, particularly those with high tax rates, gain in this context by shifting from formula apportionment to separate accounting or factor taxation? To examine this issue, let us assume that all firms have zcro net profits, and face the same $\bar{\tau}$ and $\bar{\tau}_{K}$, an assumption less strongly motivated here than the equivalent assumption in section $I$.

Under formula apportionment, a given firm's tax payments to state $i$ are

$$
T_{i}=\tau_{i}\left(\alpha K_{i} B_{K}+(1-\alpha) W_{i} B_{w}\right)
$$

where $B_{K}$ is the tax base per unit of capital, and $B_{W}$ is the tax base per unit of payroll:

$$
B_{K}=\left(\frac{\pi}{K}+d\right) ; B_{W}=\left(\frac{\pi}{W}+\frac{d K}{W}\right)
$$

These two tax bases are common to all states, and additional investment in a single state affects welfare in all states by changing both tax bases.

With $\bar{\tau}$ and $\bar{\tau}_{K}$ identical across firms, $T_{i} / K_{i}$ is also identical and equal to state $i$ 's tax revenue per unit of capital. Using the first-order conditions for profit maximization, it is possible to show that 


$$
\begin{aligned}
& \frac{T_{i}}{K_{i}}=\tau_{i}\left[\frac{\alpha W}{K}+(1-\alpha) \frac{W_{i}}{K_{i}}\right] \frac{d K}{(1-\bar{\tau}) W} \\
&=\frac{\partial \pi}{\partial K_{i}}+\frac{L_{i}}{K_{i}} \frac{\partial \pi}{\partial L_{i}}-\left\{\frac{\bar{\tau}}{(1-\bar{\tau})^{2}} \frac{d K}{W}\left[\alpha\left(\tau_{i}-\bar{\tau}_{K}\right) \frac{W}{K}+(1-\alpha)\left(\tau_{i}-\bar{\tau}_{W}\right) \frac{W_{i}}{K_{i}}\right]\right. \\
&\left.+\frac{(1-\alpha) \bar{\tau}_{W}}{1-\bar{\tau}} \frac{d K}{W}\left[\frac{W}{K}-\frac{W_{i}}{K_{i}}\right]\right\}
\end{aligned}
$$

The term in the curly brackets reflects the marginal impacts of $W_{i}$ and $K_{i}$ on $B_{W}$ and $B_{K}$. Under scparate accounting, where each state bas its own tax base, this term does not appear. Thus, state $i$ 's tax revenue per unit of capital under separate accounting, or factor taxes on property and payroll, satisfies

$$
\frac{T_{i}}{K_{i}}=\frac{\partial \pi}{\partial K_{i}}+\frac{L_{i}}{K_{i}} \frac{\partial \pi}{\partial L_{i}}
$$

Suppose now that the corporate tax using formula apportionment is replaced in cvery state with one using separate accounting (or with a property tax) which implies the same marginal capital distortions $\left(\partial \pi / \partial K_{i}\right)$, and with payroll taxes which maintain the same marginal labor distortions $\left(\partial \pi / \partial L_{i}\right)$. To isolate distributional considerations, let us impose assumptions $A$ and $B$ from soction I.B. Then this change in tax systems leaves all equilibrium prices in the economy unchanged and causes no reallocation of factors between states. However, state $i$ 's tax revenue per unit of capital rises by the expression in curly brackets in equation (21). But total tax revenue summed across sti.ies, remains unchanged. As in section I.B, we find that states with high tax rates should gain revenue at the 
expense of states with low tax rates when factor taxes are used rather than formula apportionment, but now this occurs only if capital-labor ratios are not too much lower in high tax rate states than elsewhere.

C. Political instability

Does each state still gain by reducing its corporate tax rate to zero, replacing the lost revenue with a property tax and a payroll tax? Let us again assume that $\bar{\tau}$ and $\bar{\tau}_{K}$ are identical across firms; and that each state is "small", so that its tar policy does not significantly alter the net return to capital, $\bar{\tau}$, or $\bar{\tau}_{K}$. If the replacement property tax rate, $t_{i}$, and the payroll tax rate, $s_{i}$, arc each set so as to preserve the initial distortions, then $T_{i}=\alpha d \tau_{i} /(1-\tau)^{2}$ and $s_{i}=(1-\alpha) d \tau_{i} K / W(1-\bar{\tau})^{2}$ State $i$ 's tax tevenue per unit of capital now satisíes

$$
\frac{T_{i}}{K_{i}}=\tau_{i}\left[\alpha \frac{W}{K}+(1-\alpha) \frac{W_{i}}{K_{i}}\right] \frac{d K}{(1-\tau)^{2} W}
$$

Inspection with the first line in eq. (21) shows that the policy change raises $T_{i} / K_{i}$ by the fraction $\bar{\tau} /(1-\bar{\tau})$. Thus, any state can colloct more revenue with factor taxes without changing the tax distortions affecting factor usage.

D. Government decision-making

If all states were identical, and all were to shift simultanoously from factor apportionment to property taxation and payroll taxation, then, as before, one source of externality through which one state's behavior affocts welfare in other states, is eliminated. If there are no other externalities present, then this is a social gain. 
Unlike in section I.D, however, the direction of the externality depends on the factor price elasticity of the capital-labor ratio.

To examine the direction of the externality, let us utilize the model outlined in section I.D., naturally extended to allow state $i$ 's welfare to depend on the marginal distortions in both the labor and capital market:

$$
V_{i}=V\left(T_{s i}, \partial \pi / \partial K_{i}, \partial \pi / \partial L_{i}\right)
$$

With all states assumed to be identical, they all chcose the same $\tau_{i}$ and possess the same $K_{i} / W_{i}$. Thus, the term in the curly brackets in equation (21) must cqual zero, implying that there are no transfers of revenue between states. However, each state takes into account the marginal cffect of its tax rate on this term when choosing this tax rate. As scen from equation (21), a rise in a single state's tax rate from its equilibrium value (where all $\tau_{i}$ 's are identical) will raise $K_{i} \frac{\partial \pi}{\partial K_{i}}+L_{i} \frac{\partial \pi}{\partial L_{i}}$ above $T_{i}$ and thercby transfer revenue to othex states, if $K_{i} / W_{i}$ does not fall too much below $K / W$. In this case, there is a positive cxternality, which can be expected to reduce the equilibrium $T_{s i}$ below its efiicient level. In general, however, the externality can be either pasitive or negative.

\section{Three factor formula}

When three factors are used in the formula apportionment, the analysis becomes much more complicated, and only a few results are reported. One immediate question in setting up the three factor case is whether sales, as defined in the tax formula, represent sales at origin or at destination. Most state tax 
formulas use sales at destination, so we explore this case. We assume in addition that output can be transported between states without cost.

Under these assumptions, the objective of the firm is to choose $K_{i}, L_{i}$, and $S_{i}$ so as to maximize

$$
R=\pi-\sum_{i} \frac{\tau_{i}}{3}\left(S_{i} / S+K_{i} / K+W_{i} / W\right)(\pi+d K)
$$

For simplicity, we now ignore differences in weights assigned to each of the three factors.

The first-order conditions for $K_{i}$ and $L_{i}$ change in a straight-forward way from those in section II, becoming

$$
\frac{\partial \pi}{\partial K_{i}}=\frac{\bar{\tau} d}{(1-\bar{\tau})}+\frac{\left(\tau_{i}-\bar{\tau}_{K}\right) d}{3(1-\bar{\tau})^{2}}
$$

and

$$
\frac{\partial \pi}{\partial L_{i}}=\frac{w_{i}\left(\tau_{i}-\bar{\tau}_{W}\right) d K}{3 W(1-\bar{\tau})^{2}} .
$$

Here, $\bar{\tau}=\left(\bar{\tau}_{K}+\bar{\tau}_{W}+\bar{\tau}_{S}\right) / 3$, where $\bar{\tau}_{S}=\Sigma S_{i} \tau_{i} / S$. These first-order conditions are almost identical to those in section $I$, differing only in the definition of $\bar{\tau}$ and in the appearance of weights of $1 / 3$ instead of $\alpha$ and $(1-\alpha)$.

Given zero transportation costs, the firm can sell its output across states in a pattern independent of the location of its production. The gain to selling a unit in state $i$ rather than state $j$ equals 


$$
\left(P_{i}-P_{j}\right)(1-\bar{\tau})-\frac{d K\left[P_{i}\left(\tau_{i}-\bar{\tau}_{S}\right)-P_{j}\left(\tau_{j}-\bar{\tau}_{S}\right)\right]}{3 S(1-\tau)}
$$

where $P_{i}$ and $P_{j}$ represent the output prices in each of the states. If the firm is indifferent to selling in the two states, then the relative prices in the two states must satisfy ${ }^{17}$

$$
\frac{P_{i}}{P_{j}}=\frac{C-\tau_{j}}{C-\tau_{i}}
$$

where $C=\left[\bar{\tau}_{S} / 3+S(1-7)^{2} / d K\right]$.

If all firms in equilibrium have the same value of $C$, then cquation (29) characterizes relative prices of the output. However, in general, $C$ can differ across firms. If so, inspection shows that firms with relatively large values of $D \equiv S(1-7)^{2} / d K$ will concentrate their sales in relatively high tax rate states, and face relatively high values of $\bar{\tau}_{S}$. Assume to the contrary that $\bar{\tau}_{S}$ is the same for two firms with different values of $D$. But then $C$ is larger for the firm with the larger value of $D$, and the percent surcharge it would need to be willing to sell in the high tax rate state, as shown in cquation (29), would be smaller. Therefore, a firm with a relatively large value of $D$ would shift its sales toward the high tax rate state, raising its value of $\bar{\tau}_{S}$ and conversely. It $\partial D / \partial \bar{\tau}_{S}$ is sufficiently negative, then thi:s process may bring the values of $C$ for the two firms into equality (eliminating any competitive differential at the margin) before a corner solution in the location of sales is reached.

Since large values of $D$ are associated with production in low tax rate states, 
unless capital-labor elasticities are too high, the tax law creates incentives for cross-hauling of output. Production in low tax rate states will be sold noure heavily in high tax rate states, and converscly. Under separate accounting, no such distortions exist.

We have not attempted to generalize the rest of the analysis to the three-factor case. However, the complexity of the analysis, which prevented us from proceeding further, is in itself one of the main conclusions of the paper.

\section{Alternative formulas}

Throughout this paper we have described various ways in which incentives under existing forms of formula appontionment differ from those created when separate accounting is used. Are there alternative formulas which approximate more closely the incentives implicd by scparate accounting, yet still maintain the administrative advantages of existing law?

Under separate accounting, taxable profits for a firm in state $i$ would be $d K_{i} /\left(1-\tau_{i}\right)$, and total taxable profits would equal $d \sum_{i} K_{i} /\left(1-\tau_{i}\right)$. Consider then the formula assigning the fraction $\left(K_{i} /\left(1-\tau_{i}\right)\right) / \sum_{j}\left(K_{j} /\left(1-\tau_{j}\right)\right)$ of any firm's total profits to state $i$. After-tax profits of the firm now equal

$$
R=\pi-\frac{\sum_{i} \tau_{i} K_{i} /\left(1-\tau_{i}\right)}{\sum_{j} K_{j} /\left(1-\tau_{j}\right)}(\pi+d K)
$$

If in equilibrium $R=0$, then the first-order conditions for the optimal vaiues of $K_{i}$ 
are simply $\partial \pi / \partial K_{i}=\tau_{i} d /\left(1-\tau_{i}\right)$, exactly the same as under scparate accounting. ${ }^{18}$ Labor demand decisions and sales decisions are undistorted, also as under separate accounting. Yet this formula is at least as easy to administer as existing law.

Complications arise when any of the assumptions are relaxed. If the tax parameter $d$ varies by state, the formula giving the same incentives as separate accounting would assign the fraction $\left(K_{i} d_{i} /\left(1-\tau_{i}\right)\right) / \sum_{j}\left(K_{j} d_{j} /\left(1-r_{j}\right)\right)$ of a firm's profits to state $i$. The tax parameter $d_{i}$, however, woild be a complicated function of depreciation schedules, tax credits, interest rates, and any other investment related incentives, making this formula very difficult to administer. Similar administrative complications arise if the formula must be modified to reflect different rate brackets which are often present under state corporate tax law. Furthermore, if firms receive true profits in equilibrium, then no feasible formula would maintain the incentives existing under separate accounting. To do so, the pure profits must be assigned to the state in which they are earned, yet, short of separate accounting, insufficient information is available to do this. The formula proposed in equation (30) should still be an improvement over existing law, however.

\section{Conclusions}

Using formula apportionment rather than separate accounting may simplify the administration of a corporation tax. It also distorts further the incentives faced by both individual firms and individual states. 
For any given distortions to the costs of capital and labor inputs to production in each state, under our competitive assumptions the same total amount of tax revenue is raised under formula apportionment, under separate accounting, or under taxation of factor inputs. To this extent, formula apportionment is no more costly a way to raise tax revenue than these alternative taxes. However, while total revenue is the same, tax revenue in high tax rate states is normally lower under formula apportionment then under cither of the other taxes, while tax revenue in low tax rate states is higher. These cross-subsidies under formula apportionment lead states to choose inefficiently low tax rates, cverything else cqual, rclative to those chosen under either of the alternative taxcs. In fact, given the crosssubsidies, any state has the incentive to reduce its corporate tax rate under formula apportionment to zero, maximizing its subsidy, then replacing the lost revenue with one of the alternative taxes.

In addition, a corporate tax under formula apportionment crcates additional types of distortions not present when the alternative taxes are used. Under formula apportionment, factor price distortions vary in general among firms within a state, normally putting multistate firms at a competitive advantage, thereby artificially encouraging firms to merge across state lines. Such a tax also creates incentives for cross-hauling of output, with production in low tax rate states sold in high tax rate states, and conversely.

There is therefore a clcar efficiency cost in using formula apportionment to simplify the administration of a corporate tax. In contrast, taxes on factor inputs 
are yet casier to administer (since a corporate tax using formula apportionment requires the measurcment of factor inputs as well as profits), yet crcate none of the extra distortions to firm or state decision-making described above. 


\section{Footrotes}

1. The U.S. Supreme Court has recently ruled that a state may apply formula apportionment to all profits of a firm, and not just to domestic profits.

2. See, for example, Musgrave [1972] or United Nations [1974].

3. See, for example, McLure $[1980,1981]$.

4. Pretax economic profits are simply revenues minus net of corporate tax payments to all factor inputs.

5. In general, $d$ can be computed by taking the difference between one and the present value of all deductions resulting from a dollar investment, and multiplying this difference by the sum of the depreciation rate and the opportunity cost of capital (the real after-tax interest rate). If only oconomic depreciation is allowed, a standard simplifying assumption, then $d$ equals the real after-tax intcrest rate. Recent estimates suggest that under U.S. corporate tax law, $d$ is negative, at least for equipment. (Sce the Economic Report of the President for 1982 and 1983, or Fullerton-Gordon [1983]). Throughout the text of this paper, however, we assume that $d$ is positive under state corporate tax laws. Most results reverse if $d$ is negative.

6. These first-order conditions and various of the observations have been reported previously in Mieszkowski-Morgan (1982), Frisch (1983), and Johnston (1983). 
7. We assume that each firm uses a positive amount of capital. This assumption is maintained throughout the paper.

8. Detailed provisions of a corporate tax, even with separate acconnting, may create incentives for mergers. For example, firms with tax losses gain by merging with profitable firms.

9. Aggregate revenue, summed across states, remains unchanged, however.

10. It is notationally simpler to analyse a proportional tax, but the results are the same with a corporate tax based on separate accounting.

11. Of course, our constant returns to scale assumption precludes firms from being made worse off in the long run, since exuilibrium net profits always equal zero. Given putty-clay capital, however, the switch to apportioning world-wide profits would reduce net profits below zero initially.

12. For simplicity, no attempt is made to describe separately which prices adjust to absorb the tax distortion.

13. Sce, for cxample, Wilson (1983) and Zodrow and Micszkowski (1983) for a demonstration of this claim.

14. If other sources of externalities exist which in themselves lead states to choose tax rates which are inefficiently high, however, then on socond best grounds this tax change would have ambiguous cffects on utility. For discussion of the various spillovers to nonresidents, søe Gordon [1983]. 
15. The proof of Theorem 2 can casily be extendal to show that the theorem holds when the condition on $\sigma$ is replaced by the assumption that the production function is Cobb-Douglas.

16. Proofs of these two assertions involve straightforward applications of the arguments in Theorem 1, and are available from the authors.

17. McLure (1980) and Mieszkowski-Morgon (1982) also note this effect of formula apportionment on relative output prices.

18. The tax base shared by all states is now $B=(\pi+d K) /\left(\sum_{j} K_{j} /\left(1-\tau_{j}\right)\right)$. If $R=\mathbf{0}$ in equilibrium, then $B$ equals $d$ and is unaffected at the margin by a change in $K_{i}$. Thus the externality present under the previous formula is now absent. 


\section{APPENDIX}

\section{Proofs of Therrems}

Notation: A firm's output in state $i$ can be defined as a function of its demands for capital and labor in state $i: Y_{i}=f\left(K_{i}, L_{i}\right)$. This function is juentical across firms. We normalize the output price to one. Let $r$ be the net return to capital. Then

$$
R=(1-\bar{\tau})\left[\sum_{i} f\left(K_{i}, L_{i}\right)-\left(r+\frac{\bar{\tau} d}{1-\bar{\tau}}\right) \sum_{i} K_{i}-\sum w_{i} L_{i}\right]
$$

where

$$
\bar{\tau}=\alpha \frac{\sum_{i} \tau_{i} K_{i}}{\sum K_{i}}+(1-\alpha) \frac{\sum_{i} \tau_{i} w_{i} L_{i}}{\sum_{i} w_{i} L_{i}}, \text { for } 0 \leq \alpha \leq 1
$$

Since scale is irrelevant under the constant returns to scalc assumption, profits can be normalized in any desired manner. We set $(1-\bar{\tau}) \sum w_{i} L_{i}$ equal to one. Let $k_{i}$ be the capital-payroll ratio in state $i\left(k_{i}=K_{i} / w_{i} L_{i}\right)$, and let $\lambda_{i}$ be the share of the firm's total payroll in state $i\left(\lambda_{i}=w_{i} L_{i} / \sum_{i} w_{i} L_{i}\right)$. Under the chosen normalization, net profits can then be written

$$
R=\sum_{i} \lambda_{i}\left[f\left(k_{i}, \frac{1}{w_{i}}\right)-\left(r+\frac{\bar{\tau}}{1-\bar{\tau}} d\right) k_{i}-1\right]
$$

where 


$$
\bar{\tau}=\alpha \frac{\sum_{i} \tau_{i} k_{i} \lambda_{i}}{\sum_{i} k_{i} \lambda_{i}}+(1-\alpha) \sum_{i} \tau_{i} \lambda_{i}
$$

Proof of Theorem 1: By the assumptions of the theorem, $\alpha=0$ in equation (A4). We need to show that a firm's profit-maximizing $\bar{\tau}$ is unique under the stated conditions. Since all firms possess the same production technology, this proves the result.

For a firm's $k_{i}$ 's to maximize profits, as defined by (A3),

$$
f_{1}\left(k_{i}, \frac{1}{w_{i}}\right)=r+\frac{\bar{\tau}}{1-\bar{\tau}} d
$$

where the subscript on $f$ denotes a partial derivative. Eq. (A5) defines the profitmaximizing $k_{i}$ as a function of $\bar{\tau}$; and it is clear that the profit-maximizing capital-labor ratios are identical across states:

$$
w_{i} k_{i}(\bar{\tau})=w_{j} k_{j}(\bar{\tau}) \text { all } i, j
$$

Note also from (AS) and the definition of the substitution elasticity, $\sigma$, that

$$
\frac{d k_{i}(\bar{\tau})}{d \bar{\tau}}=\left[\frac{1}{f_{11}\left(k_{i}, \frac{1}{w_{i}}\right) k_{i}} \frac{d}{(1-\bar{\tau})^{2}}\right] k_{i}=\frac{\sigma}{\theta_{L} f_{1}} \frac{d k_{i}}{(1-\bar{\tau})^{2}}
$$

where $\theta_{L}$ is labor's income share, defined in terms of marginal products (i.e., $\left.\theta_{L}=f_{2}\left(K_{i}, L_{i}\right) \cdot L_{i} / f\left(K_{i}, L_{i}\right)\right)$. By (A6), both $\sigma$ and $\theta_{L}$ are identical across states.

Suppose now that, contrary to the theorem, there are two different profitmaximizing $\bar{\tau}^{\prime} s, \bar{\tau}^{\prime}$ and $\bar{\tau}^{\prime \prime}$. Let $\left\{\lambda_{i}^{\prime}\right\}$ and $\left\{\lambda_{i}{ }^{\prime}\right\}$ be the $\lambda_{i}$ 's associated with $\bar{\tau}^{\prime}$ and $\bar{\tau}^{\prime \prime}$ : 


$$
\bar{\tau}^{\prime}=\sum_{i} \tau_{i} \lambda_{i}^{\prime} \text { and } \bar{\tau}^{\prime \prime}=\sum_{i} \tau_{i} \lambda_{i}^{\prime \prime}
$$

For $0 \leq a \leq 1$, define the functions,

$$
\begin{aligned}
\lambda_{i}(a) & =a \lambda_{i}^{\prime}+(1-a) \lambda_{i}^{\prime \prime} \\
\bar{\tau}(a) & =a \bar{\tau}^{\prime}+(1-a) \bar{\tau}^{\prime \prime} \\
R(a) & =\sum_{i} \lambda_{i}(a)\left[f\left(k_{i}(\bar{\tau}(a)), \frac{1}{w_{i}}\right)-\left(r+\frac{\bar{\tau}(a)}{1-\bar{\tau}(a)} d\right) k_{i}(\bar{\tau}(a))-1\right]
\end{aligned}
$$

By assumption,

$$
\max _{0 \leq a \leq 1} R(a)=R(0)=R(1)=0
$$

Thus, there exists some $\hat{a} \in(0,1)$ such that

$$
\frac{d R(\hat{a})}{d a}=0 \text { and } \frac{d^{2} R(\hat{a})}{d a^{2}} \geq 0
$$

We shall use (A13) to derive a contradiction.

Differentiating (A11) yields

$$
\begin{aligned}
& \frac{d R(\hat{a})}{d a}=\sum_{i} \frac{d \lambda_{i}}{d a} k_{i}\left[f\left(1, \frac{1}{w_{i} k_{i}}\right)-\left(r+\frac{\bar{\tau}(\hat{a})}{1-\bar{\tau}(\hat{a})} d\right)\right] \\
& -\frac{\overline{\tau^{\prime}-\bar{\tau}^{\prime \prime}}}{\left(1-\bar{\tau}(\hat{a})^{2},\right.} d \sum \lambda_{i} k_{i}=0,
\end{aligned}
$$

where it is henceforth understood that all variables are evaluated at $\hat{a}$. Using (A5), it is casily seen that

$$
f\left(1, \frac{1}{w_{i} k_{i}}\right)-\left(r+\frac{\bar{\tau}}{1-\bar{\tau}} d\right)=\frac{\theta_{L}}{\theta_{K}}\left(r+\frac{\bar{\tau}}{1-\bar{\tau}} d\right),
$$


where $\theta_{i}$ is factor $i$ 's income share, defined in terms of marginal products. Since these shares are identical across states (by (A6)), each side of (A15) is independent of $i$. Thus, (A14) and (A15) imply that

$$
\sum_{i} \frac{d \lambda_{i}}{d a} k_{i}=\frac{\bar{\tau}^{\prime}-\overline{\tau^{\prime \prime}}}{1-\bar{\tau}(\hat{a})}\left(\frac{d}{r(1-\bar{\tau})+d \bar{\tau}}\right)\left(\frac{\theta_{K}}{\theta_{L}}\right)\left(\sum_{i} \lambda_{i} k_{i}\right)
$$

By differentiating (A14) and using (A5), (A7), and (A16), we obtain

$$
\frac{d^{2} R(\hat{a})}{d a^{2}}=\frac{\left(\bar{\tau}^{\prime}-\bar{\tau}^{\prime}\right)^{2}}{(1-\bar{\tau}(\hat{a}))^{3}}\left(\sum_{i} \lambda_{i} k_{i}\right) d \cdot\left[-2 \frac{\theta_{K}}{\theta_{L}} \frac{d}{r(1-\bar{\tau})+d \bar{\tau}}-2+\frac{\sigma}{\theta_{L}} \frac{d}{r(1-\bar{\tau})+d \bar{\tau}}\right],
$$

Under our assumption that $d \leq r$, it is clcar from (A17) that

$$
\frac{d^{2} R(\hat{a})}{d a^{2}}<0 \text { if } \quad \sigma<2
$$

Thus, (A13) is violated when $\sigma<2$.

Q.E.D.

Proof of Theorem 2. Let $R(\alpha, \lambda)$ denote maximum profits conditional on $\alpha$ and $\lambda$, where $R$ has been normalized as before, and $\lambda$ is the share of total payroll in state 1. Assume, contrary to the theorem, that for some $\alpha^{\prime}$, profits are maximized at $\lambda=0$ and $\lambda=1$ :

$$
R\left(\alpha^{\prime}, 0\right)=R\left(\alpha^{\prime}, 1\right)=0
$$

Then $R\left(\alpha^{\prime}, \lambda\right) \leq 0$ at all $\lambda$. Under the conditions of the thoorem, we shall show 
that

$$
R\left(\alpha^{\prime}, \lambda\right)>0 \text { for some } \lambda \in(0,1)
$$

This contradiction establishes the desircd result.

For each $\lambda$, let $\alpha(\lambda)$ be the $\alpha$ which minimizes $R(\alpha, \lambda)$; and define

$$
R^{*}(\lambda)=R(\alpha(\lambda), \lambda)
$$

Clearly, $R(\alpha, 0)$ and $R(\alpha, 1)$ are independent of $\alpha$. Then, by (A19),

$$
R *(0)=R^{*}(1)=0
$$

We shall prove that

$$
R^{*}(\lambda)>0 \text { for some } \lambda \in(0,1)
$$

This result clearly establishes (A20), thercby completing the proof.

If $\alpha(\lambda)$ equals 0 or 1 for a given $\lambda \in(0,1)$, then our previous results imply that $R^{*}(\lambda)$ is positive under the conditions of the theorem. 'Thus, assume that $\alpha(\lambda)$ lies between zero and one for all $\lambda$ between zero and one. Then $\alpha(\lambda)$ satisfies the firstorder condition

$$
\frac{\partial R(\alpha(\lambda), \lambda)}{\partial \alpha}=0
$$

where it is henceforth understood that $\lambda \in(0,1)$. For (A24) to hold, a marginal change in $\alpha$ must not alter the value of $\bar{\tau}$ associated with each $\lambda$. By (A.4), $\bar{\tau}$ stays constant if and only if the profit-maximizing $k_{1}$ and $k_{2}$ at $\alpha(\lambda)$ and $\lambda$ are identical. Let $k^{*}(\lambda)$ denote this common value of $k_{1}$ and $k_{2}$. The first-order condition for $k^{*}(\lambda)$ is obtained by differentiating (A3): 


$$
\sum_{i} \lambda_{i} f_{1}\left(k^{*}(\lambda), \frac{1}{w_{i}}\right)=\left(r+\frac{\bar{r}}{1-\bar{\tau}} d\right)
$$

We now use (A25) and the assumptions of the theorem to show that

$$
\frac{d^{2} R^{*}(\lambda)}{d \lambda^{2}}<0 \text { if } \frac{d R^{*}(\lambda)}{d \lambda}=0
$$

Conditions (A26) and (A22) establish (A23), as desired.

First differentiate (A3) with respect to $\lambda$ and set the result equal to zero:

$$
\frac{d R *(\lambda)}{d \lambda}=\left(f^{1}-f^{2}\right)-\frac{\tau_{1}-\tau_{2}}{(1-\tau)^{2}} d k=0
$$

where $f^{i}=f\left(k^{*}(\lambda), \frac{1}{w_{i}}\right)$ and $k=k^{*}(\lambda)$. Then

$$
\frac{d^{2} R^{*}(\lambda)}{d \lambda^{2}}=\left[\left(f_{1}^{1}-f_{1}^{2}\right)-\frac{\tau_{1}-\tau_{2}}{(1-\tau)^{2}} d\right] \frac{d k^{*}(\lambda)}{d \lambda}-2 \frac{\left(\tau_{1}-\tau_{2}\right)^{2}}{(1-\tau)^{3}} d k
$$

From (A25), we obtain

$$
\frac{d k *(\lambda)}{d \lambda}=\frac{1}{-\sum \lambda_{i} f_{11}^{i}}\left[\left(f_{1}^{1-} f_{1}^{2}\right)-\frac{\left(\tau_{1}-\tau_{2}\right) d}{(1-\tau)^{2}}\right]
$$

If $\theta_{K}^{i}$ is capital's income share in state $i$, then

$$
f_{1}^{i}=\theta_{k}^{i}(f / k)
$$

Eqs. (A27) and (A30) imply that there exists some $b$ such that

$$
\min \left(\theta_{K}^{1}, \theta_{K}^{2}\right) \leq \boldsymbol{b} \leq \max \left(\theta_{K}^{1}, \theta_{K}^{2}\right)
$$

and 


$$
f_{1}-f_{1}^{2}=b\left[\frac{\tau_{1}-\tau_{2}}{(1-\tau)^{2}} d\right]
$$

Substituting (A29) and (A32) into (A28) gives

$$
\frac{d^{2} R^{*}(\lambda)}{d \lambda^{2}}=\frac{(1-b)^{2}}{-\sum \lambda_{i} f_{11}^{i}}\left[\frac{\left(\tau_{1}-\tau_{2}\right)^{2} d^{2}}{(1-\tau)^{4}}\right]-2 \frac{\left(\tau_{1}-\tau_{2}\right)^{2} d}{(1-\tau)^{3}} k
$$

where, by (A31), $(1-b)^{2}<1$.

Observe next that

$$
-\sum_{i} \lambda_{i} f_{11}^{i}=\frac{1}{k 0} \sum_{i} \lambda_{i} f_{1}^{i} \theta_{L}^{i}
$$

If $\vec{\theta}_{L}$ is the minimum of $\theta_{L}^{1}$ and $\theta_{L}^{2}$, then (A25), (A34), and the assumption that $d \leq r$ give

$$
-\sum_{i} \lambda_{i} f_{11}^{i} \geq \frac{\bar{\theta}_{L}}{k \sigma} \frac{d}{(1-\bar{\tau})}
$$

From (A33) and (A35), we obtain the condition

$$
\frac{d^{2} R^{*}(\lambda)}{d \lambda^{2}}<0 \text { if } \quad \sigma<2 \bar{\theta}_{L}
$$

Q.E.D. 


\section{References}

Economic Report of the President, Washington, D.C.: U.S. Government Printing Office, 1982-3.

Frisch, Daniel J.: "Issues in the Taxation of Foreign Source Income," in Behavioral Simulation Methods in Tax Policy Analysis, ed. by Martin Feldstein, Chicago: University of Chicago Press, 1983.

Fullerton, Don and Roger H. Gordon: "A Recxamination of Tax Distortions in General Equilibrium Moxdels," in Behavioral Simulation Methods in Tax Policy Analysis, ed. by Martin Fcldstein. Chicago: University of Chicago Press, 1983.

Gordon, Roger H.: "An Optimal Taxation Approach to Fiscal Federalism," Quarterly Journal of Economics.

Johnston, James L.: "Unitary Taxation: A Free Lunch?", mimeo, 1983.

McLure, Charles E.: "The Elusive Iricidence of the Corporate Income Tax: The State Case," Public Finance Quearterly, 9(1981), 395-413.

- "The State Corporate Income Tax: Lambs in Wolves' Clothing," in The Economics of Taxation, ed. by Henry Aaron and Michael Boxkin, Washington, D.C.: Brookings Institution, 1980.

Mieszkowski, Pcter and John Morgan: "The National Effocts of Differential State Corporate Income Taxes on Multi-State Corporations," mimeo, 1982. 
Musgrave, Peggy: "International Tax Base Division and the Multinaticnal Corporation," Public Finance, 27(1972), 394-413.

United Nations: The Impact of Multinational Corporations on Development and on International Relations, Technical Papers: Taxation, New York: United Nations, 1974.

Wilson, John D.: "A Theory of Inter-Regional Tax Competition," mimeo, 1983.

Zodrow, George R. and Peter Mieszkowski, 'Pigou, 'Ticbout, Property 'Taxation and the Under-Provision of Local Public Goods," mimeo, 1983. 